\title{
AN INTEGRATED METHODOLOGY \\ FOR THE DIGITIZATION, SURVEY AND VISUALIZATION OF SANTA MARIA PATIRION'S CHURCH
}

\author{
C. Ruggiero ${ }^{\mathrm{a}}$, A. Gallo ${ }^{\mathrm{a}}$,, A. Lio ${ }^{\mathrm{b}}$, A. Zappani ${ }^{\mathrm{b}}$, G. Fortunato ${ }^{\mathrm{b}}$, M. Muzzupappa ${ }^{\mathrm{a}}$ \\ ${ }^{a}$ Departrment of Mechanical Engineering, University of Calabria, 87036 Rende (CS), Italy - carm.ruggiero@gmail.com, \\ alessandro.gallo@unical.it,muzzupappa@unical.it \\ ${ }^{\mathrm{b}}$ Department of Civil Engineering, University of Calabria, 87036 Rende (CS), Italy - alio@unical.it, antzapp@live.it, \\ giuseppe.fortunato@unical.it
}

KEY WORDS: Laser scanning; 3D modeling; Cultural Heritage; Immersive visualization.

\begin{abstract}
:
In this paper we present a methodology for the digitization, the survey and the visualization of a 3D model built from a large scale object that combines the use of different hardware, software and geometric data. The results are a detailed virtual model used for the documentation of the preservation status of the artifact and a simplified 3D model for the navigation with an immersive stereoscopic visualization system.
\end{abstract}

\section{INTRODUCTION}

The demand for 3D digital models of historical monuments in the field of archaeological and architectural applications is currently growing (Salonia, 2009), and digital systems and environments are more and more used as a tool for preservation, reconstruction, documentation, research and promotion (Bruno, 2010). Photorealistic 3D models may be developed for very small objects or whole buildings. These models are generally developed by means of 3D scanning techniques, in order to acquire the objects in a faithful way (Fowles, 2003, Boulanger, 1988, Akca, 2006, Tsioukas, 2004). Generally, when the digital documentation is focused on monuments, buildings or entire sites, 3D models are created with terrestrial laser scanners, thanks to their high acquisition speed and precision. This process allows to obtain geometric models of great accuracy (Lichti, 2004), (Ergun, 2010). Recently, the availability of increasingly powerful hardware and software has brought to the spread of photographic techniques that allow to create models with an acceptable accuracy and reduced costs (Shashi, 2007). Even if these technologies provide a detailed description of the geometry, on the other hand the data post-processing necessary to produce a lightweight but realistic model is often prohibitive for the huge amount of data. Therefore, the development of Virtual Reality applications dedicated to the fruition of Cultural Heritage still remains a complex task, especially if these techniques have to be applied to buildings or complex sites. In this paper we describe the methodology that has been used for the survey, the analysis and the $3 \mathrm{D}$ reconstruction of the Patirion Church (Rossano - Italy). After drawing a brief historical frame, the paper describes the acquisition procedure and the subsequent geometrical analysis. For the survey we employed a Leica HDS3000 Time-of-Flight laser scanner and a Leica TCR $407 p$ total station. Views and sections derived from the point cloud were used to conduct a thorough diagnostic study of the building. Finally, the paper presents a contribution to overcome the above mentioned problems, by suggesting some guidelines for the post-processing of very dense point clouds, in order to produce a 3D model completed with high resolution textures mapped from a set of photos. The virtual model was then made accessible through an interactive application implemented using Virtools ${ }^{\mathrm{TM}}$, that allows a realtime navigation in the entire building.

\section{THE CASE STUDY}

The St. Maria Nuova Odigitria's Church (called Patirion) is located 605 meters above sea level, on a branch of the Sila mountains facing the Ionian Sea between Rossano and Corigliano, in the province of Cosenza (Calabria, Italy). The church (Figure 1), which is part of a larger architectural complex that includes also some small remains of an ancient monastery, is the result and the emblem of the successful fusion of three civilizations, Byzantine, Arab and Norman.

The church, built in stone, features a 3-aisled basilica plan, a sober façade dominated by a central rose window and three Byzantine domes. The part of the church in better condition is the exterior one, composed by three apses decorated with the typical Norman architectural elements.

The floor of the church is the part that enriches the most the entire complex: in front of the main entrance there is a large mosaic. For further information relating to the mentioned site please see (Orsi, 1929).

\section{PHASES AND TOOLS OF METHODOLOGY}

The following paragraphs provide a detailed description of the different phases of the process (Table 1). It has to be noted that the data reported starting from the modeling phase are related only to the exterior of the church. The interior part is currently under processing, therefore no quantitative data are available.

* Corresponding author. 


\subsection{D Data Capture of the Church}

For the survey we adopted an approach which consists in the integration of the data obtained by the time-of-flight laser scanner Leica HDS3000 and the total station Leica TCR 407p.
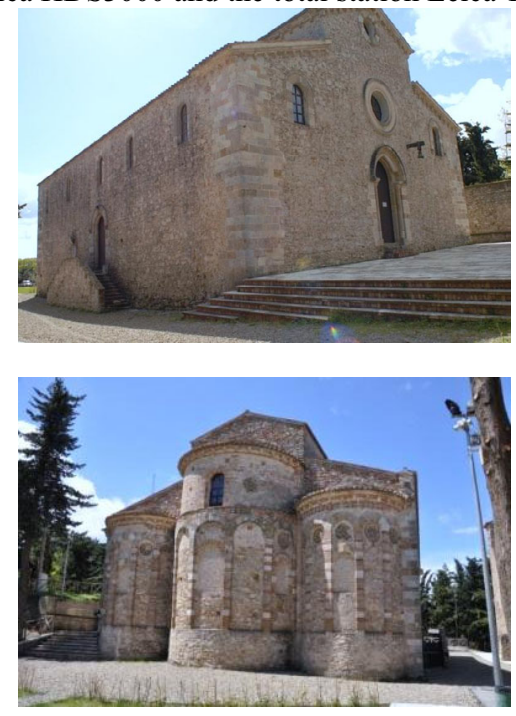

Figure 1: St. Maria Nuova Odigitria's Church (Patirion)

The laser scanner employed can operate in a wide field of view $\left(360^{\circ} \mathrm{H} \times 270^{\circ} \mathrm{V}\right)$, and is able to generate a cloud of 1800 points per second with an accuracy of $\pm 2 \mathrm{~mm}$ on the range of
$1 \div 50 \mathrm{~m}$. The total station has an angular accuracy of 7" and a range of the laser beam of $200 \mathrm{~m}$.

The process requires the arrangement of the targets to be acquired both with the laser scanner and the total station to facilitate the positioning and alignment of the scans. The notable dimensions of the building led to a division of the work in different daily phases. We have developed an open polygonal curve with control points, having as vertices the points of the station and as points of interest the targets and several easily identifiable references in place. The entire complex has been covered with a polygonal of 10 station points, while for the acquisition of the point cloud of the outer surface of the church, 10 Scanworlds (single positioning of the laser) were required (Figure 2).

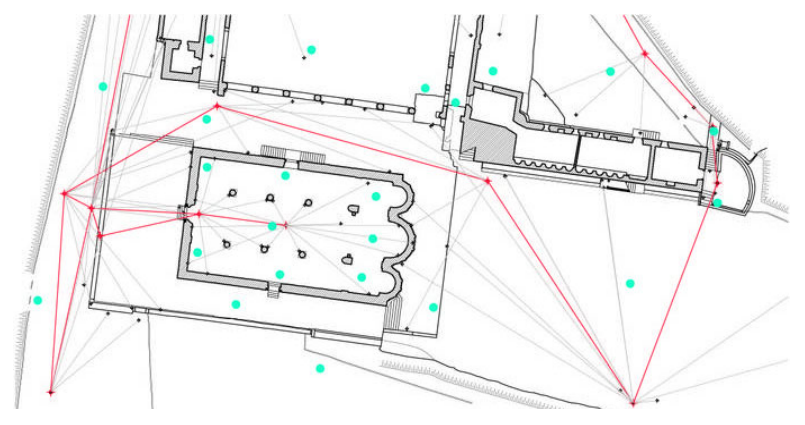

Figure 2: Positioning of Scanworlds (blue) and station points (red) for the internal and external acquisitions.

\begin{tabular}{|c|c|c|c|c|}
\hline Phases & Activities & Hardware & Software & Data \\
\hline 3D Data Capture & $\begin{array}{l}\text { Integration of data related } \\
\text { to the scans of TOF laser } \\
\text { scanners and total station. }\end{array}$ & $\begin{array}{l}\text { TOF Laser Scanner Leica } \\
\text { HDS3000; } \\
\text { Total station Leica TCR } \\
\text { 407p. }\end{array}$ & Cyclone (Leica) & $\begin{array}{l}\text { Point cloud } \\
\text { (87 millions) }\end{array}$ \\
\hline Data Analysis & $\begin{array}{l}\text { Extraction of technical } \\
\text { drawings for a diagnostic } \\
\text { documentation of the } \\
\text { preservation state }\end{array}$ & \multirow{3}{*}{$\begin{array}{l}\text { Workstation with Intel }{ }^{\circledR} \\
\text { Core TM i7-2600 CPU @ } \\
3.40 \mathrm{GHz}, 8 \mathrm{~GB} \text { Ram and } 64 \\
\text { bit operative system. } \\
\text { Digital cameras }\end{array}$} & CloudWorx (Leica) & $\begin{array}{l}10 \text { Technical } \\
\text { drawings }\end{array}$ \\
\hline \multirow{2}{*}{ 3D Modelling } & \multirow{2}{*}{$\begin{array}{l}\text { Refining and decimation of } \\
\text { point cloud and creation of } \\
\text { the triangulated model. }\end{array}$} & & Bundler - PMVS2 & $\begin{array}{l}\text { 3D model from } \\
\text { photos }\end{array}$ \\
\hline & & & Meshlab & $\begin{array}{l}\text { Triangulated } \\
\text { model }\end{array}$ \\
\hline Texturing & $\begin{array}{l}\text { Perspective correction, crop } \\
\text { and equalization of photos. } \\
\text { 3D Mapping of the photos } \\
\text { on model }\end{array}$ & $\begin{array}{l}\text { Digital Cameras (Nikon } \\
\text { D90, D200 and D5000) }\end{array}$ & $\begin{array}{l}\text { Gimp } \\
\text { Bundler }\end{array}$ & 200 images \\
\hline Fruition & $\begin{array}{l}\text { Development of an } \\
\text { application for the } \\
\text { exploration and the } \\
\text { navigation of the } 3 \mathrm{D} \text { model } \\
\text { in a virtual environment }\end{array}$ & $\begin{array}{l}\text { Workstation with } 50 " 3 \mathrm{D} \mathrm{TV} \\
\text { monitor- full HD }\end{array}$ & Virtools (Dassaults) & $\begin{array}{l}\text { 3D model with } \\
1,000,000 \\
\text { polygons }\end{array}$ \\
\hline
\end{tabular}

Table 1: Phases, tools and data of our methodology 
The interior of the church has been acquired with 8 Scanworlds at higher resolution, in order to avoid acquisitions with an angle of the laser beam smaller than 30. To check the proper alignment of the point clouds of the interior, we have also run an overall Scanworld for the whole interior. The Scanworlds have been aligned by means of a series of targets and subsequently processed with the Cyclone software, reaching a maximum alignment error of $6 \mathrm{~mm}$.

In order to create the texture of both the interior and exterior, more than 500 images were acquired using different highresolution cameras.

\subsection{Data analysis}

For the restitution of the canonical drawings (plans, elevations and sections) we followed a procedure that allows to obtain flat sections directly from the point cloud while working in a CAD environment, using the CloudWorx software: in this work environment, reference systems and planes were created and saved in the database.

The management of the large amount of information obtained from the scan has been simplified, as it is possible to extract only the band of points needed to generate the section. With this method, by proceeding through different planes along the point cloud, we obtain the various plans, elevations and sections (Figure 3).

The diagnostic element is extracted and analyzed from the information provided by the geometric model. In particular, we found a series of evidences during the examination of the extracted surveys:

$\rightarrow$ a flaw of horizontality of the crowning cornice of the central apse of $23 \mathrm{~cm}$;

$\rightarrow$ the central apse has a failure towards South of about $11 \mathrm{~cm}$;

$\rightarrow$ the left side of the central apse has an out-of-plumb towards the outside of about $10 \mathrm{~cm}$;

$\rightarrow$ the masonry present above the central apse has a concavity of about $22 \mathrm{~cm}$;

$\rightarrow$ the shelves that support the cornice are poorly finished and differ from each other;

$\rightarrow$ the slope of the floor is turned towards the apses, featuring a difference in height between the two ends of the nave of 31 $\mathrm{cm}$;

$\rightarrow$ the axes of the North and South portals differ from each other by $15 \mathrm{~cm}$;

$\rightarrow$ the perimeter openings present at the average height of $+6.70 \mathrm{~m}$ are not aligned with the arcades and are located at variable height, with some asymmetric splays as well;

$\rightarrow$ no opening is aligned with those below;

furthermore, from an examination of the side survey, we note that the building has a gradual drawdown with respect to the ground level, if referring to the constructive height of the rear façade.

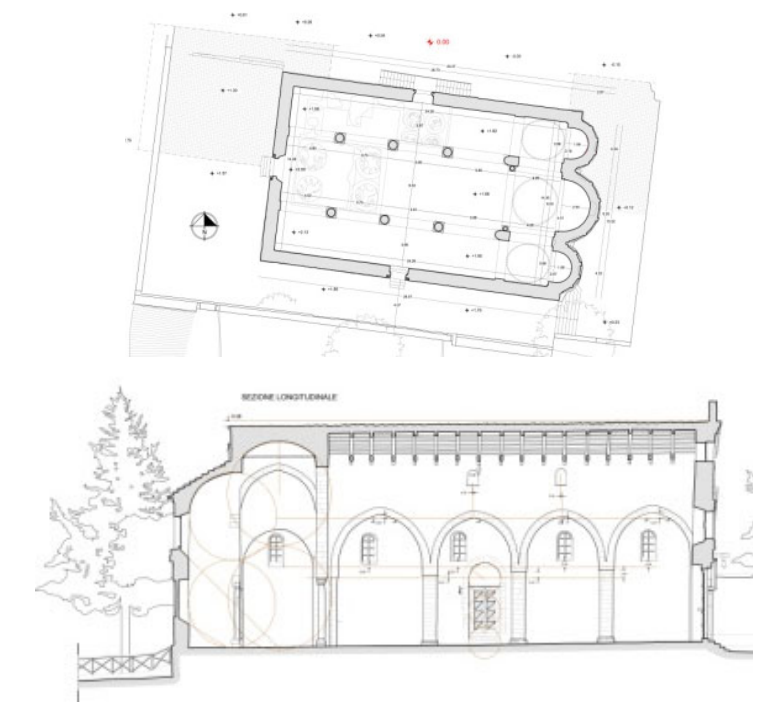

Figure 3: Some geometrical drawings useful for the diagnostic documentation of the preservation status.

\subsection{D modelling}

For the registration of multiple scans in a single reference system, the positions measured with the total station have been used. The result is a single point cloud of about 87 million points, that integrates internal and external scans of the Church. In order to be post-processed, it has been exported from Cyclone.

The obtained model results to be unmanageable: any operation on the cloud turns out to be very slow, thus preventing any realtime interaction. The first step was the differentiation of the scans belonging to the interior and the exterior of the building in two files, thus obtaining two clouds of about 31 million points and 56 million points, respectively (Figure 4).
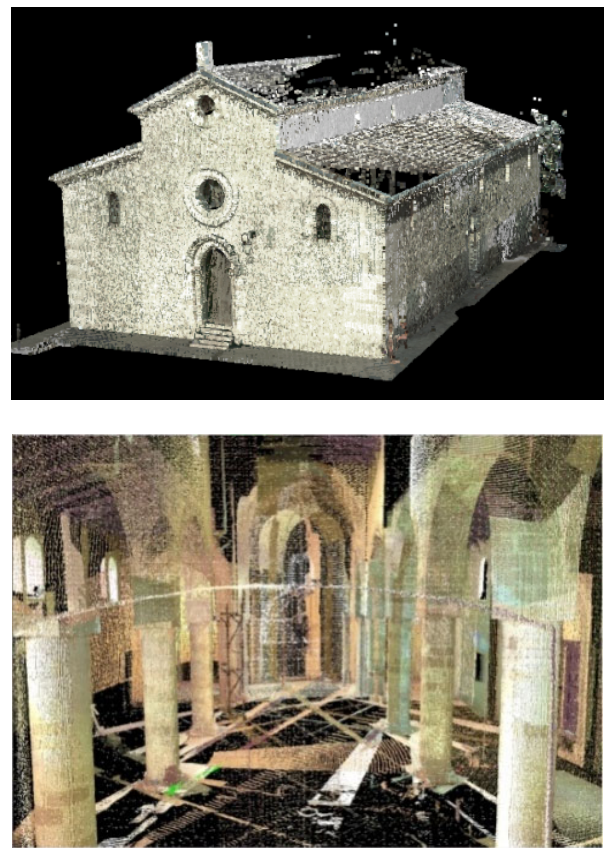

Figure 4: (a) external cloud with 56 million points; (b) internal cloud with 31 million points. 
Both models have very dense areas and also areas with few points because there are some parts not optically accessible from the scanning positions. At present, we focused on the 3D modeling of the exterior of the church. So, hereinafter, we will refer exclusively to the reconstruction process of the exterior. The open source mesh processing software MeshLab has been employed for a first filtering of the noise due to the acquisition. After an additional sub-sampling filter useful to reduce the amount of data without losing quality, the initial point cloud of 56 million points has been reduced to 10 million points. Subsequently by means of the Poisson Surface Reconstruction Algorithm included in Meshlab, we obtained a triangulated mesh of about 20 million polygons.

\subsection{D model refinement}

The surface reconstructed from the data acquired with the laser scanner is affected by noise due to surface properties and lighting condition and some missed areas due to occlusions. Furthermore, some elements have been modified after the restoration intervention, such as the stairs on the left side of the church (Figure 5 a). Thus we have decided to integrate the model reconstructed with the laser scanner, with a surface reconstructed by using a multi-view stereo technique (Seitz, 2006) on the sequence of images taken for texturing purpose. In particular the SFM (Structure from Motion) software Bundler (Snavely, 2007) has been used to compute the camera position in 3D space. Then, the multi-view software PMVS2 (Furukawa, 2007) has been used to create a model of about 8 million points and 15 million polygons. (Fig 5 b). The model has been computed up to an unknown scale factor, so it is necessary to scale the $3 \mathrm{D}$ point cloud obtained only by pictures by using a reference know distance.

The next step involves the alignment of the new 3D data to the one obtained with the laser scanner, by using the ICP (Iterative Closest Point) algorithm. Finally, the cleaning and mesh editing tool provided with Meshlab, has been used to fill the holes and remove all the surface defects on the merged model (Fig $5 \mathrm{c}$ ). The final model consist in about 30 million polygons, decimated to 1 million in order to produce a model navigable in real time maintaining a good accuracy.

\subsection{Texturing}

Each scanner has its proper camera to acquire RGB images, but with a quality that was too poor to be used for a photorealistic model. For this reason it was necessary to use a high-definition digital camera to reconstruct all the details in a reliable way. Some procedures of colour, exposure, lighting and contrast correction were done, on about 200 pictures that have been taken for the exterior part of the church. The texture-mapping procedure is based on a photogrammetric process, that performs image orientation automatically without using calibrated cameras or control points such in (Valanis, 2010).

In particular the SFM software Bundler is used to compute the camera positions ad a sparse reconstruction of the scene, that have been scaled and aligned with the refined model (fig 6 a). Since the camera position are known, it is possible to map the images on the refined mesh by projection mapping (Figure $6 \mathrm{~b}$ ), adopting a weighted average in order to avoid artefacts on the resulting texture due to changes in lighting and point of view. With this approach will not be necessary to find manually control points on both images and 3D model such in (Stathopoulou, 2010). Figure 7 shows the final refined model mapped with the high quality texture.
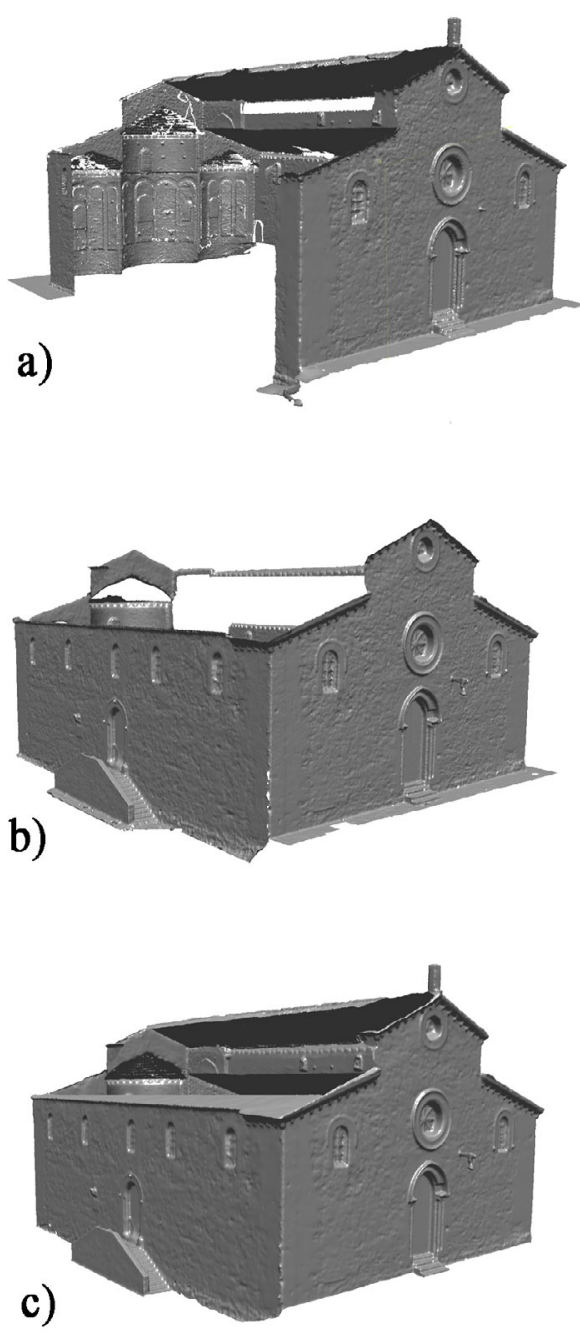

Figure 5: Laser scanner model (a), 3D reconstruction by multiview stereo (b), merged model (c).

\subsection{Fruition of the Virtual Model}

The textured 3D model has been exported in VRML format to keep the texture mapping within the visualization environment. This format allows us to manage a repository with highly detailed data that can be made available to the public.

The software application was developed using the Virtools package and run on workstation connected to a 50" full HD active stereo monitor (Figure 8). The user interface consists of a trackball and four buttons. The user can choose between a manual and an automatic first-person navigation system. In manual navigation, the user can decide the direction where to move, by translating and rotating the virtual camera; the system uses the uses the Collision Detection to prevent the penetration into the surfaces. The automatic navigation, however, makes the camera follow a predefined path curve in a loop until the user decides to return to manual navigation. 


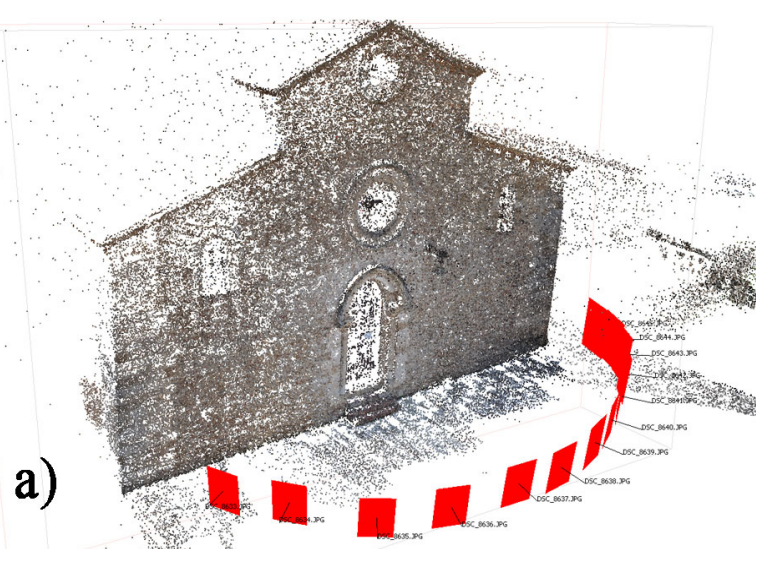

church and so we have not yet published our data on the web (i.e. www.europeana.eu).

a)
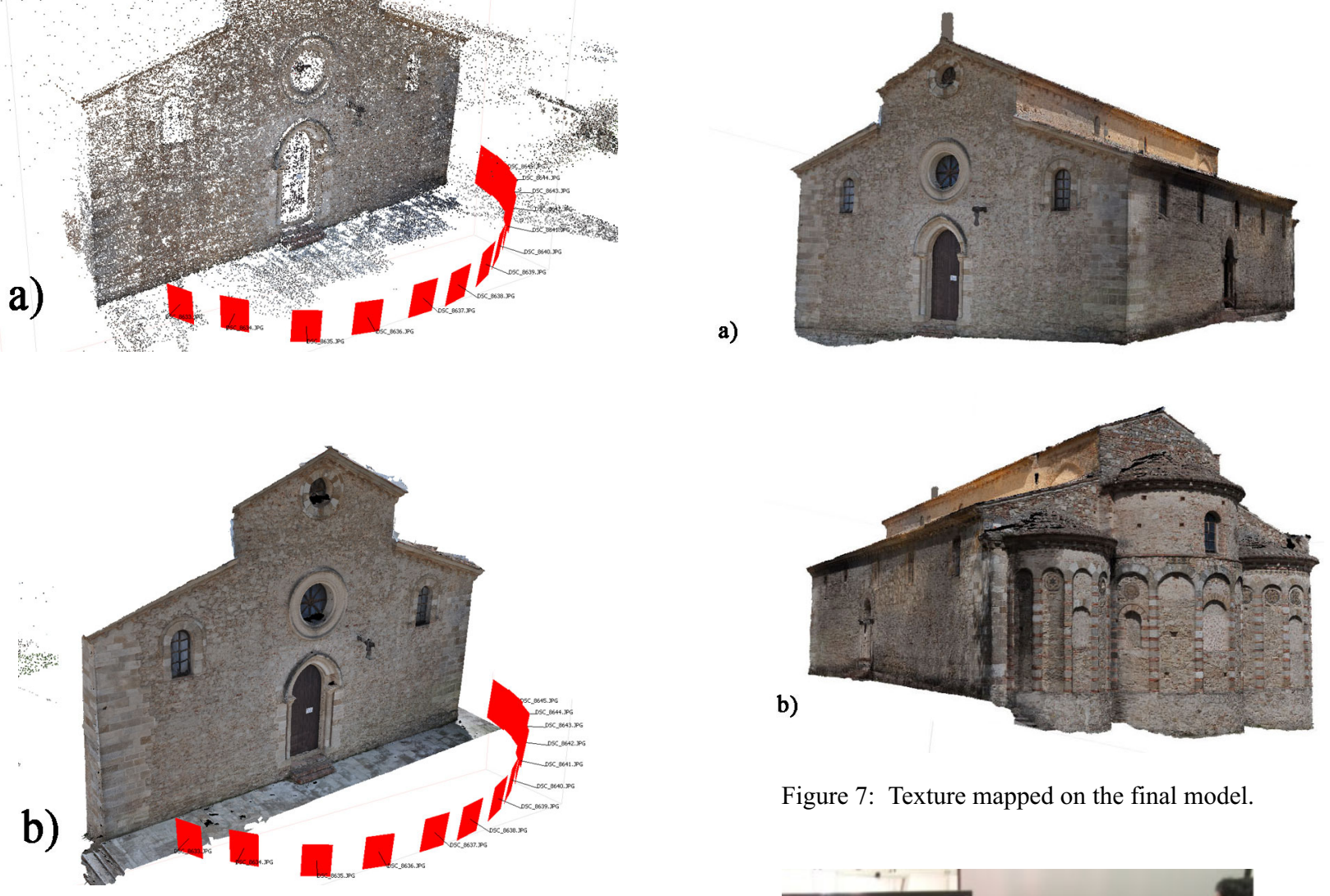

Figure 7: Texture mapped on the final model.

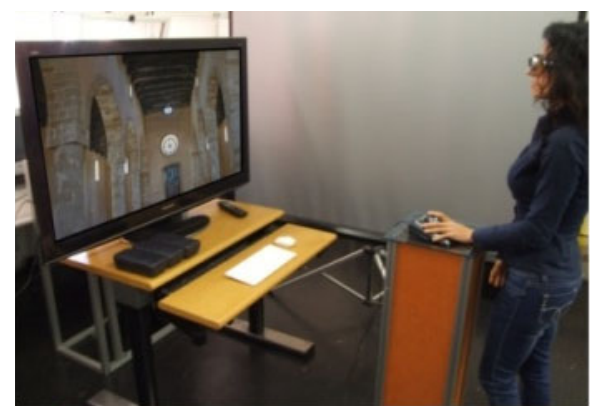

Figure 8: System for the fruition.

of accurate and interactive 3D models with a high level of detail but easily manageable. The goal was to obtain virtual models that could be analysed both for the generation of technical documentation and the real time visualization on virtual reality systems.

The described methodology was applied to the reconstruction of the church of St. Maria Nuova Odigitria, located in Rossano (Southern Italy). The obtained results fulfill both the defined goals, but only after a very onerous data post-processing.

For the preparation of the documentation concerning the preservation status of the artefact, it was necessary to carry on a scan campaign that required many days of work and a long and complex processing of the technical drawings.

The data processing work required to make the model navigable and interactive in a virtual environment was even more onerous. The main difficulty lies in finding the right balance between texture resolution and number of triangles, i.e. to maintain a good balance between the manageability of the model in real time and the accuracy of the reconstruction. The obtained results show a good integration of details and architectural features in the overview of the structure on a large scale. Currently, the $3 \mathrm{D}$ reconstruction refers to the outside of the

\section{REFERENCES}

References from Journals:

Bruno, F. et al., 2010. From 3D reconstruction to virtual reality: A complete methodology for digital archaeological exhibition, Journal of Cultural Heritage 11 (2010) 42-49.

Ergun, B., 2010. A novel 3D geometric object filtering function for application in indoor area with terrestrial laser scanning data, Optics \& Laser Technology 42, pp.799-804.

Fowles, P.S., Larson, J.H., Dean C., Solajic, M. The laser recording and virtual restoration of a wooden sculpture of Buddha, Journal of cultural heritage 4 (2003) 367-371.

Lichti, D., 2004. A resolution measure for terrestrial laser scanners, In: International Archives of Photogrammetry, Remote Sensing and Spatial Information Sciences 34, Part B5, pp. 552558. 
Salonia, P. et al., 2009. Multi-scale cultural heritage survey: Quick digital photogrammetric systems, Journal of Cultural Heritage 10S (2009) e59-e64.

Shashi, M., Jain, K. Use of photogrammetry in $3 \mathrm{~d}$ modeling and visualization of buildings. ARPN Journal of Engineering and Appliedsciences, Vol 2(2), 37-41, 2007.

Snavely, N., Seitz, S.M. and Szeliski, R. Modeling the World from Internet Photo Collections. International Journal of Computer Vision (2007).

\section{References from Proceedings and Books:}

Akca., D., Remondino., F., Novàk, D., Hanusch, T., Schrotter, G., Gruen, A. Recording and modeling of cultural heritage objects with coded structured light projection systems, in: Proceedings of 2nd International Conference on Remote Sensing in Archaeology, "From Space To Place", Rome, 4-7 December 2006 (BAR International Series 1568), pp. 375-382

Boulanger, P., Rioux, M., Taylor, J., Livingstone, F. Automatic replication and recording of museum artifacts. In: Proceedings of 12th International Symposium on the Conservation and Restoration of Cultural Property, Tokyo, Japan 1988, pp. 131-147.

Furukawa, Y. and Ponce, J. Accurate, Dense, and Robust MultiView Stereopsis. IEEE Computer Society Conference on Computer Vision and Pattern Recognition, 2007.

Orsi, P. Le chiese basiliane della Calabria, Vallecchi Editore Firenze 1929.

Seitz, S.M., Curless, B., Diebel, J., Scharstein, D., Szeliski, R. A comparison and evaluation of multi-view stereo reconstruction algorithm. CVPR, 2006 pp.519-52.

Stathopoulou, E. K., Lerma, J. L., Georgopoulos, A. Geometric documentation of the almoina door of the cathedral of Valencia, in Proceedings of EuroMed2010 $3^{\text {rd }}$ International Conference dedicated on Digital Heritage, Limassol, Cyprus, 2010.

Tsioukas, V., Patias, P., Jacobs, P.F. A Novel System for the 3D Reconstruction of Small Archaeological Objects, in: Proceedings of XXth Congress of ISPRS, Vol, XXXV, Part B5, ISSN:1682-1750, Istanbul, Turkey, 2004.

Valanis, A., Fournaros, S., Georgopoulos, A. Photogrammetric texture mapping of complex objects, in Proceedings of EuroMed2010 $3^{\text {rd }}$ International Conference dedicated on Digital Heritage, Limassol, Cyprus, 2010. 